\title{
Zooplankton Diversity and Dispersal by Birds; Insights From Different Geographical Scales
}

\author{
Dag O. Hessen ${ }^{1 *}$, Thomas C. Jensen ${ }^{2}$ and Bjørn Walseng ${ }^{2}$ \\ ${ }^{1}$ Department of Biosciences, University of Oslo, Oslo, Norway, ${ }^{2}$ Landscape Ecology Department, Norwegian Institute for \\ Nature Research, Oslo, Norway
}

OPEN ACCESS

Edited by:

Casper H. A. Van Leeuwen, Netherlands Institute of Ecology (NIOO-KNAW), Netherlands

Reviewed by:

David G. Jenkins,

University of Central Florida,

United States

Marc Ventura,

Spanish National Research Council

(CSIC), Spain

*Correspondence:

Dag O. Hessen

d.o.hessen@ibv.uio.no

Specialty section:

This article was submitted to Biogeography and Macroecology,

a section of the journal

Frontiers in Ecology and Evolution

Received: 25 September 2018

Accepted: 26 February 2019

Published: 20 March 2019

Citation:

Hessen DO, Jensen TC and Walseng B (2019) Zooplankton Diversity and Dispersal by Birds; Insights From Different Geographical

Scales. Front. Ecol. Evol. 7:74.

doi: 10.3389/fevo.2019.00074
Given the major ecological and evolutionary role of dispersal abilities for organisms, as well as the current interest in species' potential for further migration and colonization as a result of climatic changes or human-mediated invasions, our knowledge about dispersal abilities on spatial and temporal scales in many taxa is surprisingly limited. Zooplankton inhabit lakes and ponds that functionally are "aquatic islands" in the landscape, and both community composition and richness depend on their ability to disperse, and their post-dispersal colonization abilities. We here assess the diversity and dispersal of freshwater microcrustaceans based on three types of data; (1) > 2000 lakes on mainland Norway spanning a wide range in longitude, latitude and altitude, (2) a more limited number of ponds at Svalbard that are differently affected by migrating birds, and (3) immigration and colonization of recently constructed wetlands and man-made ponds. At all scales we discuss whether observed patterns in diversity can be explicitly linked to birds as vectors, or if confounding factors such as climate, productivity, age of locality-or other means of immigration, precludes conclusive evidence. The spatial patterns of zooplankton distribution strongly suggest that local sorting is a major determinant of richness and community composition. This sorting may not necessarily lead to similar community composition (the "quorum effect") however. Despite the fact that rapid colonization occurs at local scales, and that birds undoubtedly can transmit animals or resting stages, their role in modulating community structure and richness is still an unsettled issue due to the many confounding parameters. The fact that birds often play a dual role in shaping diversity and community composition, first by direct dispersal, and secondly via affecting post-dispersal species sorting by changing water quality and productivity, is an important aspect of zoochory. Direct experimental evidence (colonization with and without bird exclusion), or genetic analysis of zooplankton species along migration routes, would however be the only ways to establish firm evidence for this case of zoochory.

Keywords: birds, dispersal, lakes, ponds, sorting, microcrustacean zooplankton

\section{INTRODUCTION}

There are two principal drivers of biogeographical distribution patterns: the ability of species to disperse to new ecosystems, and the ability to establish permanent populations post dispersal. For the biota of lakes and ponds, living in confined "aquatic islands," the ability to spread, colonize and become established in new sites is a strong fitness component, provided post-dispersal 
establishment. The ability and mechanisms for dispersal of aquatic organisms may differ with geographical range, ecosystem connectivity, dispersal vectors, and lake specific properties. One would suspect that absence or presence in nearby lakes can be attributed to lake-specific properties. On the other hand, dispersal abilities may be hard to separate from "species sorting" due to water quality, lake or pond morphometry, flushing rate, climatic patterns, and landscape history.

The dispersal abilities of aquatic organisms is a matter of longstanding interests since Darwin's seminal studies demonstrated how birds may serve as dispersal vectors for organisms attached to plumage or feet (Darwin, 1859; Bilton et al., 2001; Bohonak and Jenkins, 2003; Simonis and Ellis, 2014). Fish and birds may also spread especially resting stages via gut survival (Banarescu, 1990; Green and Figuerola, 2005; Frisch et al., 2007; Green, 2016; Coughlan et al., 2017), which should give an advantage to species forming tough resting stages (like most cladocerans and some copepods). Resting eggs (ephippia) of cladocera may resist freezing and desiccation and hatch after extended periods (Weider et al., 1997). Ephippia may disperse by wind, water or by biological vectors (Gray and Arnott, 2011; Coughlan et al., 2017), and their facultative asexual mode of reproduction and fast growth rates (classical properties of "r-selected" organisms) should be an advantage to cladocera relative to most copepods. However, widespread endemism and provincialism and allopatric speciation within restricted areas has been reported among Daphnia populations, arguing for low gene-flow between populations (Hebert and Wilson, 1994), while also copepods may rapidly colonize recently established ponds (Cácares and Soluk, 2002; Louette and De Meester, 2005). Resting eggs in copepods may also promote dispersal, yet the comparison of the two calanoids Eudiaptomus graciloides (with diapausing eggs) E. gracilis (without) suggested that diapausing eggs was only beneficial for short distance dispersal (Zeller et al., 2006).

Given the wide, sometimes cosmopolitan, distribution of several zooplankton species (Flössner, 2000; Dussart and Defaye, 2006), the question is really why not "everything is everywhere," but rather what is the actual role of dispersal constraints and landscape history relative to colonization constraints for these tiny crustaceans? Also, the role of environmental factors relative to dispersal abilities may differ between regions and geographical scales even for the same group of organisms (de Mendoza et al., 2015).

Successful dispersal does not necessarily imply successful colonization however, and a suite of local factors including abiotic and biotic (productivity, food, competition, and predation) may shape community structure and diversity (Louette and De Meester, 2005). Thus, the real dispersal capacity can best be assessed in recently established sites with favorable conditions for most species. Over time, as these systems become "saturated," the likelihood of dispersal will remain unchanged, but the likelihood of permanent establishment will be reduced as interspecific competition increases with increased richness.

Separating between dispersal and colonization is one key issue in this context; others are the role of spatial structure and scale. Clearly higher colonization will occur in areas with high beta diversity, high density of localities and high degree of connectivity. For long distance dispersal, landscape constraints and barriers as well as climate gradients are important, and so are the migration routes of waterfowls or other vectors. Species sorting will likely also increase along spatial scales due to abiotic factors, i.e., increasing distance normally imply increasing differences in water quality properties, seasonality, productivity, and temperature. This holds especially for gradients toward lower productivity and harsher climate. Most taxa show decreased poleward diversity (Gaston, 2000), so also for freshwater zooplankton (Hessen et al., 2006). This is partly accredited to confounding factors such as temperature, productivity, and covariates of these, but also to ecosystem age and landscape history. Whether this to some extent also reflects e.g., post glaciation migration constraints, remains unsettled.

One important issue is whether local sorting also promotes community similarity which could be anticipated if local habitats shared common biotic or abiotic properties. Such a "quorum effect" (Jenkins and Buikema, 1998) would be expected to be more likely late in succession in nearby sites, while less so early in succession among distant sites (Jenkins, 2006). Jenkins (2006) did however not find support for a local sorting quorum effect in a number of experimental ponds, and both colonization events and community development appeared rather stochastic.

Despite strong evidence for high local dispersal capacities of zooplankton, notably cladocera (Louette and De Meester, 2005), the role of birds in this story remains somewhat speculative (Coughlan et al., 2017). Indeed, Louette and De Meester (2005) in their thorough study did not at all discuss the mechanisms for dispersal, and did not consider this as a potential explanation for the contrasting results between their own study and that of Jenkins and Underwood (1998), who reported slow dispersal rates. They do however point to the role of local connectivity, as does Cottenie and DeMeester (2004), who also found strong impacts of local, biotic sorting. Experiments provide evidence for efficient dispersal also when cages or small ponds are covered with nets to exclude birds (Cácares and Soluk, 2002; Cohen and Shurin, 2003). For long-distance dispersal (LDD), Green and Figuerola (2005) in their thorough review of bird-mediated dispersal of zooplankton states that "... studies of LDD in aquatic systems remain in their infancy". Recent studies addressing the role of waterfowl and shorebirds for seed dispersal confirm a strong potential of endozoochory over short to moderate $(<$ $20 \mathrm{~km}$ ) distances (Bartel et al., 2018), but also long-distance dispersal across Europe (Lovas-Kiss et al., 2018). While it could be argued that plant seeds have a higher likelihood of being ingested and dispersed than aquatic animals, also resting stages of zooplankton may withstand gut passage. Moreover, this demonstrates that gut evacuation not necessarily prohibit long distance dispersal (cf. Clench and Mathias, 1992).

One could argue that what matters is the ability to disperse and colonize, irrespective of what kind of mechanism is responsible. Given the current changes in bird populations, it is however relevant to know if birds per se, and which species, that may can serve as important vectors. While there are striking declines in many common bird species, including shorebirds, associated with the cultural landscape (Donald et al., 2001; Inger et al., 2014), others are increasing. The strong increase in geese 


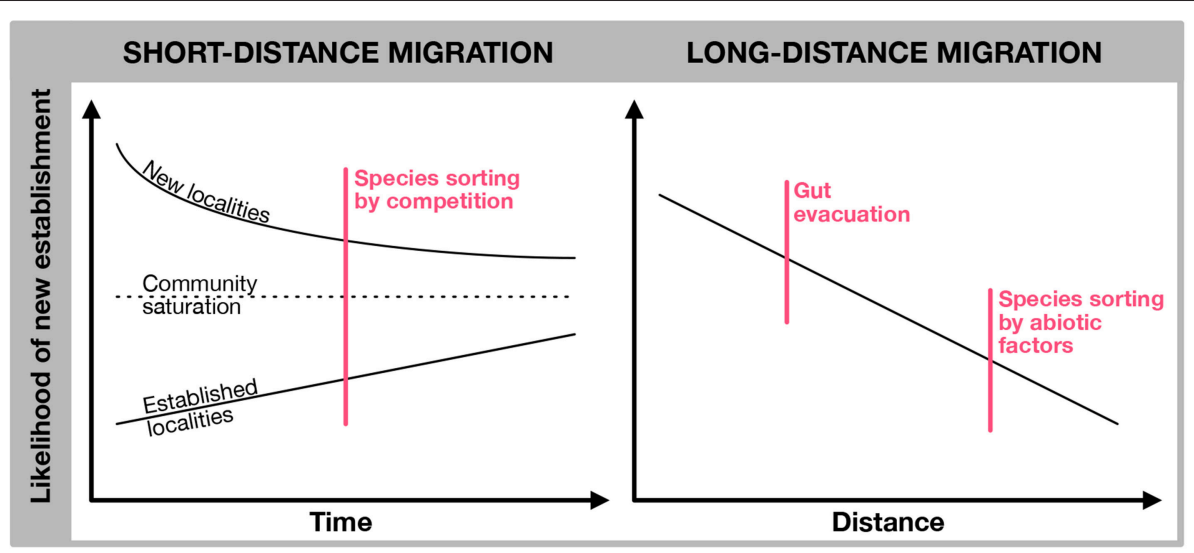

FIGURE 1 | Conceptual diagram for likelihood of dispersal, local sorting and establishment of zooplankton mediated by birds. Right panel displays the likelihood of local dispersal and establishment in recently formed and established (and species saturated) systems, respectively. In new localities with many available niches and low competition, initial likelihood of establishment is high, but will decrease over time as the system approach "saturation". A high turnover of species may still occur, and community composition may change, but the species richness does not increase. As the systems becomes established, the chance of new establishment will be small, but still the cumulative likelihood of establishment will increase over time. The right panel illustrate how likelihood of establishment decrease with migration distance, partly owing to increased likelihood of complete gut evacuation prior to arrival at the recipient site, partly due to increased likelihood of different abiotic conditions in donor sites and recipient sites. The vertical red lines represent constraints that in principle operate gradually over time and distance.

populations at high latitudes (Fox, 2010; Madsen et al., 2013) does indeed impact freshwaters over vast areas, i.e., provide LDD of freshwater taxa from overwintering sites in southern or central Europe, to stopover sites during migration, and finally to breeding sites in the high Arctic (Hessen et al., 2017). Thus, the development of bird populations may have strong impact also on aquatic biodiversity.

We here utilize three sources of data to assess if zooplankton diversity patterns and colonization can be evidently linked to birds as vectors: (1) The Norwegian mainland where zooplankton data exist from > 2000 lakes spanning a wide range in longitude, latitude and altitude. (2) The more isolated and local Svalbard case where there are links between species and clonal richness and impact by migrating bird populations, and (3) recently established ponds in the agricultural landscape, where colonization has been monitored over some years. We then discuss evidence-or lack of such-of bird-induced zoochory and propose how to proceed in this long-lasting debate, which indeed is important for understanding biodiversity patterns and also has conservation management implications.

A conceptual illustration of different mechanisms operating on different spatial and temporal scales is provided in Figure $\mathbf{1 .}$ This covers both the likelihood of dispersal per se, and physical or biological filtering or sorting mechanisms that may determine whether or not dispersed organism actually establish permanent populations. Throughout the text we will refer to these tentative mechanisms.

\section{The Norwegian Mainland}

We here explored a database on pelagic zooplankton diversity and community composition data that has been sampled since the early 1980ies. This includes altogether 2,031 localities, covering the entire mainland of Norway $\left(58^{\circ} 3^{\prime}\right.$ to $\left.71^{\circ} 4^{\prime} \mathrm{N}\right)$ and spanning a wide range in terms of altitude, area, and water quality (for details, see Walseng et al., 2006 and Hessen et al., 2007). If birds are major determinants of zooplankton dispersal, one could, based on this dataset covering such a wide geographical range, predict that this could be reflected in local diversity and community composition. More specifically, it could be expected that on top of gradients related to climate (and thus implicitly altitude, latitude and partly longitude), it should be possible to track local diversity hotspots related to migration and stopover sites, or at least temporal occurrence of species outside their natural range of distribution. For areas where there are no obvious constraints related to climate or productivity, like the costal lakes with favorable climate and often nutrient impacts from human activity, efficient zoochory by birds would even out regional differences. Confounding factors related to impact of lake size, local climate, fish predation etc. could clearly pose problems in the interpretation of bird impact, however. Also, species may be transferred but then fail to establish, or being established in particular lakes, but still unable to spread further. The likelihood of establishment will clearly be both speciesspecific and depend on the frequency and number of propagules.

Figure 2 clearly demonstrates the wide range in species richness, with the highest diversity in the south-east and a general decline with latitude, altitude and longitude (for the central areas). Notably altitude, but also longitude and latitude, provide a pronounced upper bound of species richness, but there is a major scatter due to a full range of species diversity also at low altitudes, latitudes and longitudes. Diversity and species composition changed along these geographical clines, while there were no general differences in the relative abundance of cladocera vs. copepods. The mean ratio between cladocera and copepods, including both pelagic and littoral species, was 2.8 , and with no systematic change over latitude, longitude or 


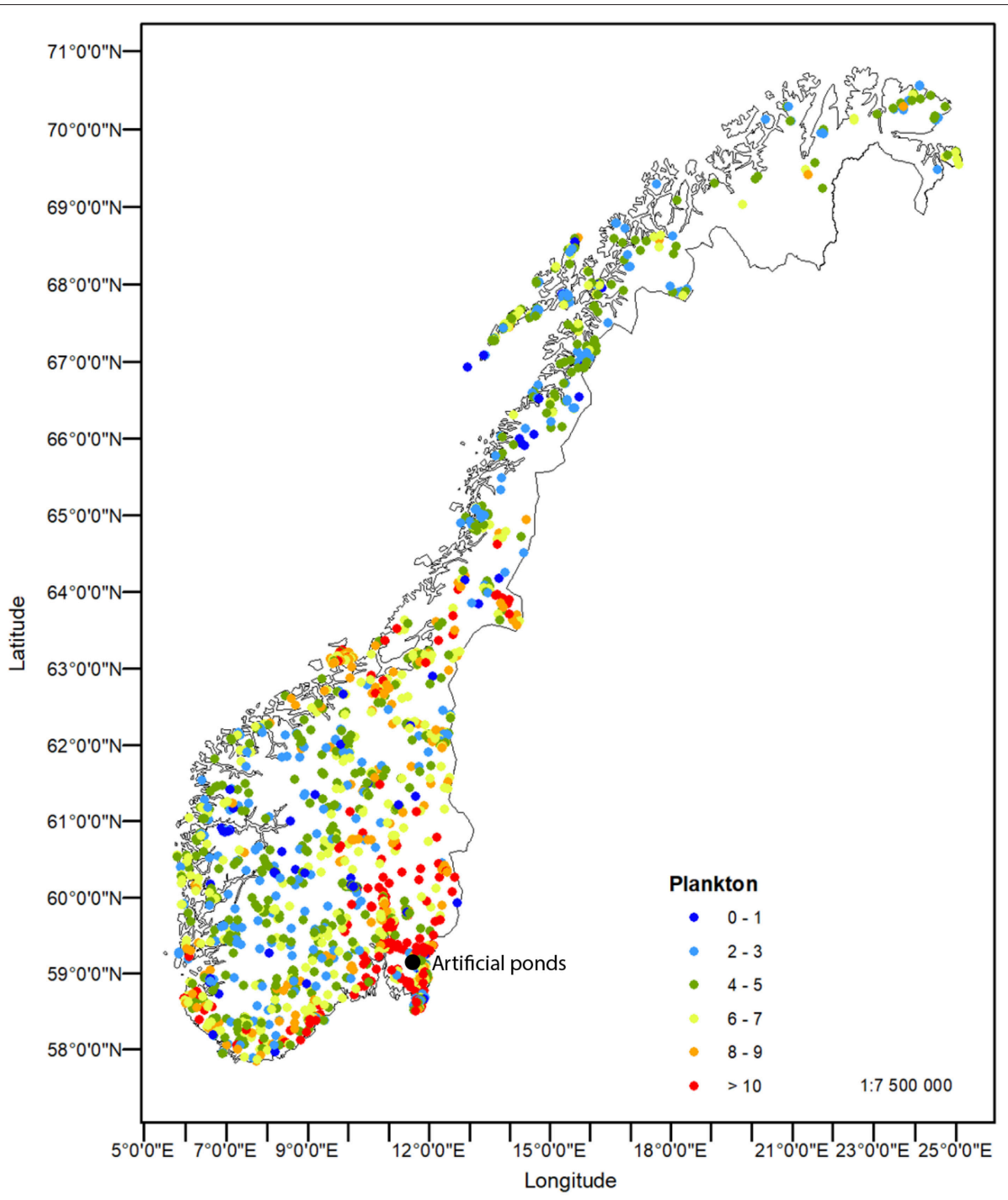

FIGURE 2 | Species richness of pelagic crustacean zooplankton across the Norwegian mainland. Color codes represents the number of species per locality. The site of the constructed, artificial ponds is indicated.

altitude. A multivariate analysis using latitude, longitude, altitude and lake area as determinants of total zooplankton (pelagic and littoral microcrustaceans) diversity in 2.937 localities, explained $22 \%$ of observed variability. The fact that $78 \%$ of observed variability in species diversity (represented by species numbers) remained unexplained, suggests that a major part of variability must be explained by local or site-specific properties like water quality, productivity, connectivity, species sorting, competition (and monopolization), or other unidentified drivers.

An extensive database of band and recapture sites for all Norwegian bird species, including shorebirds and waterfowl, is accessible (http://stavangermuseum.no/ringmerkingssentralen/ ringmerkingsatlas). While most water-related birds are coastal and display north-south migration routes, there are also common species with an extensive distribution and more random migration pattern, such as mallard (Anas platyrhynchos) and common gull (Larus canus) (Figure 3). These and a number of other water-related species should in principle provide key vectors for rapid dispersal of zooplankton throughout Norway. Most shore-birds and waterfowl perform seasonal, long distance migration, and linking central Europe, Norway and the Svalbard archipelago, e.g., barnacle geese (Branta leucopsis) and purple sandpiper (Calidris maritima) (Figure 3).

Both inland and subalpine wetlands are nesting sites for a large number of waders and ducks, but still possess modest or low zooplankton richness. Of course, this does not imply that birds do not act as vectors, since species sorting due to low temperature, low productivity, competition, predation, or other site-specific properties, may constrain permanent establishment. Hotspots for crustaceans are documented from two well-recognized stop-over sites for waterfowl in central, southern Norway. With 80 recorded species the Lake Randsfjorden (including Dokka delta) is the 


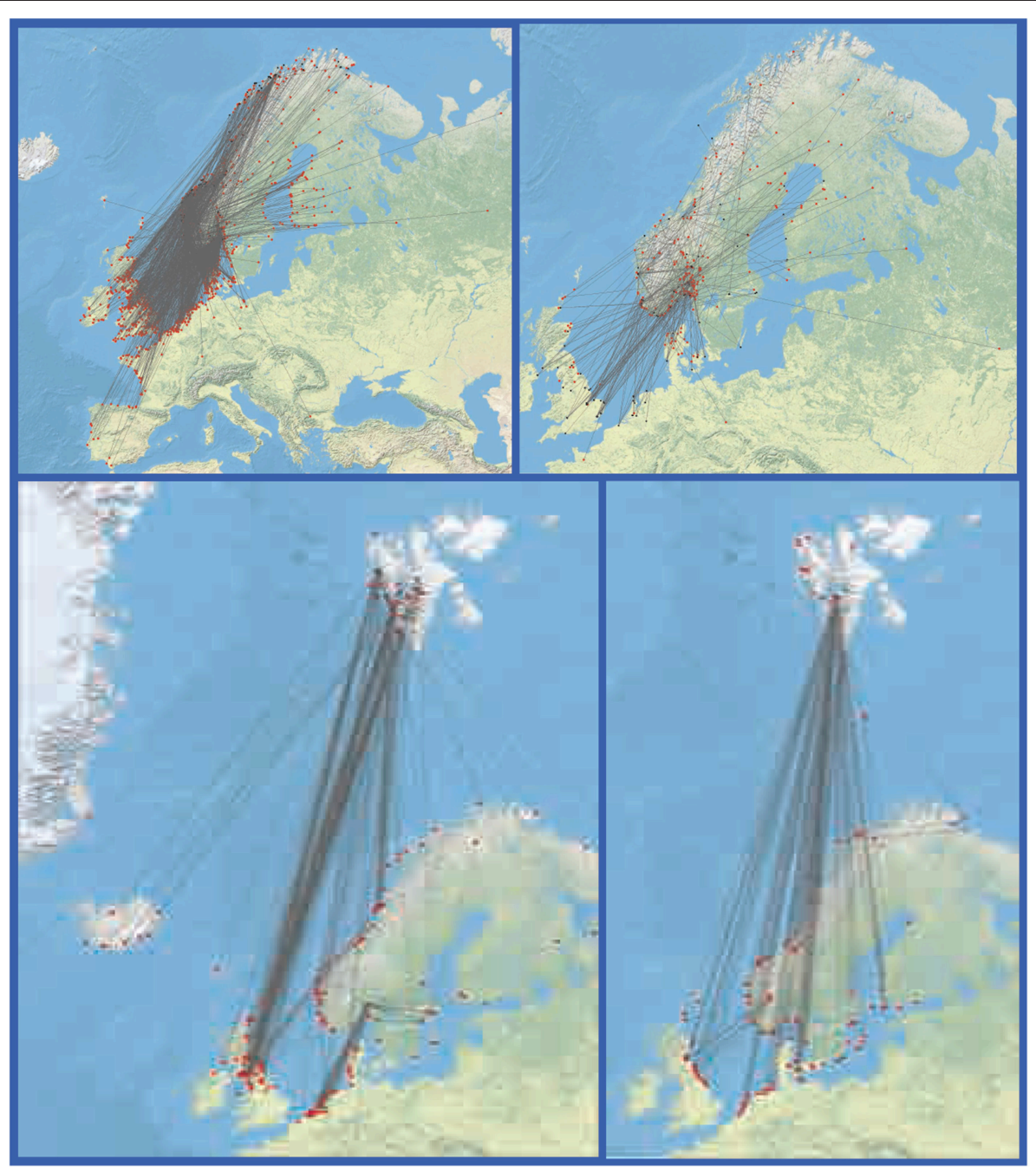

FIGURE 3 | Examples of migration routes for ringed waterfowl. Upper panel show very abundant species with a widespread migration "all over" (left: common gull-Larus canus; left: mallard Anas platyrhynchos). Lower panel are species with a coastal preference that typically link northern Europe, Norway and the Svalbard archipelago (left: purple sandpiper-Calidris maritima; right: barnacle geese-Branta leucopsis).

site with the highest number of recorded microcrustaceans in Norway, followed by the Lake Øyeren with its delta (62 species). This high diversity is partly a result of high spatial heterogeneity in habitats and water quality in the two large lakes. However, both these deltas are important stopover sites for migratory water birds, and bird-mediated dispersal could also partly explain the high microcrustacean diversity where local sorting is less pronounced owing to the favorable habitats with a high number of available niches. This is still at best circumstantial evidence since there is no conclusive evidence of bird-mediated zoochory in shaping community composition or richness at these scales, not the least due to the large number of confounding factors.

\section{The Svalbard Archipelago}

The high Arctic lakes and ponds at Svalbard provide a more species poor and geographically isolated and constrained area for testing the potential role of bird-mediated dispersal. The fact that lakes, ponds and birds are all localized in constrained coastal areas, and there is an intensive monitoring of bird populations and activities, offers a good opportunity for linking freshwater fauna to birds at a local scale. This holds especially for the geese populations that have increased dramatically over the past 30 years (Pedersen et al., 2013), is well-monitored, and that is actively exploiting and affecting the aquatic habitat (Van Geest et al., 2007; Hessen et al., 2017). Hence, this offers a possibility to link both spatial and temporal changes in the zooplankton community to the prevalence of birds within a climatologically constrained area. The presence of geese often overlaps with activity of other water-related birds, and yet waders forage directly in the freshwaters sites, geese also frequently spend time near or at the ponds where they contribute to increased concentrations of nitrogen $(\mathrm{N})$ and phosphorus (P) in the water bodies (Van Geest et al., 2007; Alfsnes et al., 2016). 
TABLE 1 | Parameter estimates for linear regression models relating cladoceran species richness to the goose abundance (judged from droppings), total- $\mathrm{N}$ and total-P [all transformed, $\left.\log _{10}(X+1)\right]$.

\begin{tabular}{llccc}
\hline $\begin{array}{l}\text { Response } \\
\text { variable }\end{array}$ & Coefficients & Estimate $( \pm$ SE) & $\boldsymbol{t}$-value & $\boldsymbol{p}$ \\
\hline $\begin{array}{l}\text { Cladoceran } \\
\text { species } \\
\text { richness }\end{array}$ & Intercept & $-1.913(0.804)$ & -2.379 & 0.026 \\
& $\begin{array}{l}\text { Goose } \\
\text { abundance } \\
\text { Total-N }\end{array}$ & $0.711(0.313)$ & 2.271 & 0.033 \\
& $1.295(0.366)$ & 3.533 & 0.002 \\
\hline
\end{tabular}

A backward selection procedure was applied for the multiple regression $(p>0.1)$. Only goose dropping abundance and total- $N$ were included in the model.

In this context we used a dataset (Walseng unpublished) from 25 Svalbard ponds along a gradient of goose impact (abundance of goose droppings) including also data on nutrient concentration and cladoceran and copepod species richness. We tested if goose impact affected species richness of cladocerans and copepods differently.

The relationship between cladoceran and copepod (cyclopoids calanoids and harpacticoids) species richness, respectively and goose abundance (using absolute dropping abundance), total nitrogen and total phosphorus was analyzed with univariate multiple linear regression. A backward selection procedure was used to exclude predictors in the multiple regression $(P>$ 0.1 ). Number of goose droppings, total- $\mathrm{N}$ and total-P were transformed $[\log 10(\mathrm{X}+1)]$ prior to analysis due to data skewness. The multiple regression of cladoceran species richness included goose dropping abundance and total-N $\left[F_{(2,22)}=\right.$ 22.161, $\left.p<0.001, R^{2}=0.668\right]$. Total-N received a stronger weight in the model than goose dropping abundance (Table 1) and accounts uniquely for 18.8 and $7.8 \%$, respectively of the variance in cladoceran species richness. An additional regression including the interaction between goose dropping abundance and total N, showed that this term was not significant. Hence, cladoceran species richness increased with increasing goose abundance and increasing total $\mathrm{N}$ concentration, but total $\mathrm{N}$ seemed to be the most important of the two predictors. Neither goose abundance, total $\mathrm{N}$ or total $\mathrm{P}$ turned out to be significant contributors for copepod species richness. Alfsnes et al. (2016) recorded the highest species and clonal diversity of Daphnia in nutrient-rich and bird-impacted localities at Svalbard and concluded that an increased species richness and clonal changes since 1992 could likely be attributed to climate change and increased bird impacts.

A recent survey of the freshwater invertebrate fauna on Svalbard (Walseng et al., 2018), demonstrated that some microcrustaceans had expanded their distributions. Additionally, a number of new species was recorded on the archipelago (Dimante-Deimantovica et al., 2018). The increasing goose populations on Svalbard during the past few decades, likely in combination with the climate warming, may have contributed to the local spreading of the native species as well the establishment of new species. In fact, the goose population may play an important role in the colonization of biota of the many newly formed water bodies as the glaciers retract due to the rising temperatures, but again we lack firm evidence for this.

\section{Recent Pond Colonization}

Six constructed ponds within a constrained watershed were studied over a 8-year period (1998-2005) (Ekeberg and Walseng, 2000; Hov and Walseng, 2003; Walseng unpubl.). These ponds are located in southern, central Norway (cf Figure 2), close to the Lake Øyeren with highest recorded diversity of freshwater taxa in Norway, and high abundance of water-fowl. There were no permanent water-bodies prior to the establishment of the ponds, but a tiny stream. Sampling of crustaceans and macroinvertebrates was performed in this stream the year before the ponds were established in 1999. The main purpose of the ponds was to increase the retention of sediments and nutrients from the stream, and they were all located within a landscape with moderate agricultural influence, pronounced topography, minimizing the dispersal by wind, or floods. The ponds differed somewhat in nutrient contents, yet this was not correlated with the number of taxa or species recorded. Rather the opposite. Following construction, the ponds were rapidly colonized, starting with oligochaets, and chironomids, followed by crustaceans, while the colonization of insects other that chironomids was slower. During the study period, 29 species of cladocerans and 26 species of copepods were identified.

Prior to the establishment of these ponds and wetlands, a close examination of four ponds draining to the local stream revealed a total of 19 cladocerans and 12 copepods (Ekeberg and Walseng, 2000). Hence, there was a restricted local inoculum of species. However, the very same year as the first sites were established in 1999, the diversity (13 cladocerans and 14 copepods) was already comparable with the very species-rich lake Lake Øyeren (situated ca $1.5 \mathrm{~km}$ from the ponds, but without direct contact). Six years later the accumulated number of species was 29 cladocerans and 25 copepods, respectively demonstrating a very fast colonization rate. We found no evidence of cladoceran dominance among the early settlers in any of the ponds. In fact, despite their lower species numbers in Norwegian freshwater (80 cladocera, 50 species of copepods, including littoral species), there was a slight copepod dominance in most of the samples (Figure 4). The cumulative number of recorded species indicated a very fast colonization up to species saturation and a likely local sorting due to competition. No specific survey of bird vectors of dispersal was performed, but the ponds were regularly visited by ducks (notably mallard), gulls and waders. The proximity to the large lake Øyeren implies a high likelihood of local dispersal by birds.

\section{DISCUSSION}

By addressing the issue of bird-mediated zoochory of zooplankton at three widely different geographical scales, we conclude (in line with many previous studies) that there are indications of this at all scales, notably on small scales, but really no firm evidence. At the largest scale, despite strong regional and clinal patterns in diversity, it is impossible to separate bird-mediated dispersal from confounding variables related to 


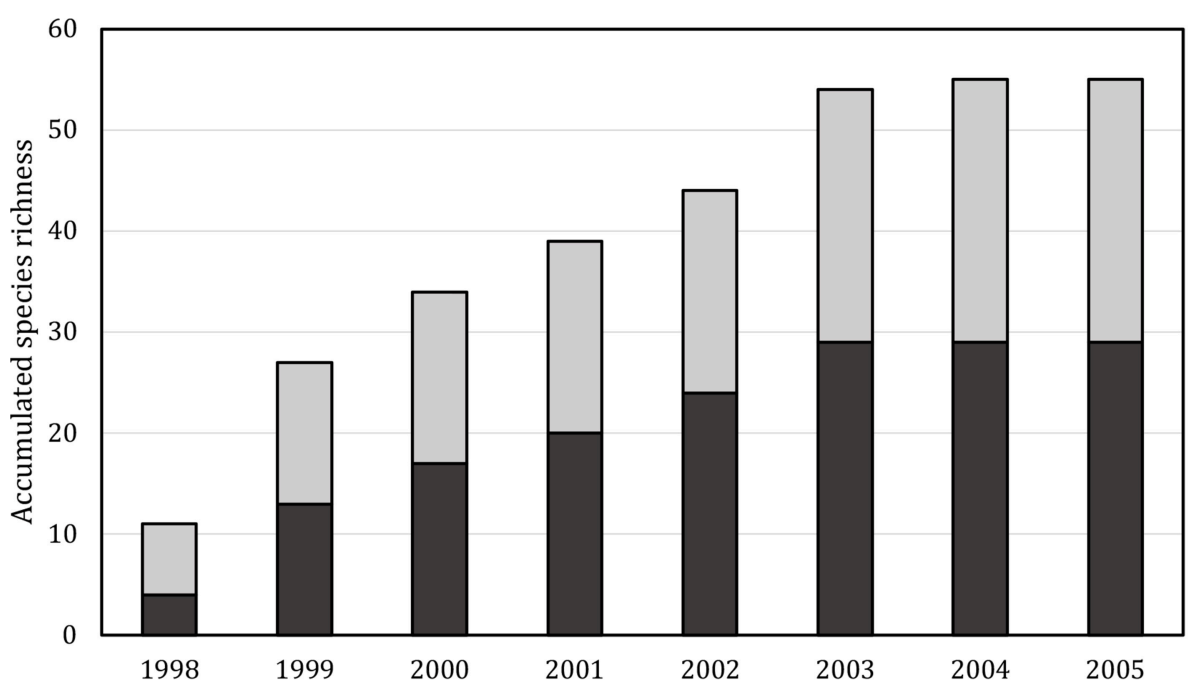

FIGURE 4 | Mean, cumulative number of observed species in the artificial pond. Black: copepods, gray: cladocera.

climate, productivity, site heterogeneity or other confounding variables. No doubt post-dispersal species sorting (e.g., failure of establishing permanent populations) add further constraints on the interpretation of zoochory. Local or regional founder effects may determine zooplankton communities for extended periods even under high dispersal rates (Shurin, 2000; De Meester et al., 2002; Ventura et al., 2014). Inland deltas that are important stop-over sites for birds possess very high diversity, but these are also productive and heterogenous habitats that anyway would offer suitable niches to many species. The main migration route of migrating water-fowls follows the coastline of Norway, but there is also an extensive migration by very abundant duck and gull species all over Norway, including inland lakes and east-west routes (cf. Figure 3 ). (The full range of migrations as well as zooplankton species distributions can be explored and visualized on http://stavangermuseum.no/ ringmerkingssentralen/ringmerkingsatlas and https://www. biodiversity.no/Pages/231126, respectively). Despite this, the diversity on the west-coast is strikingly lower than further east, and also diversity generally decreases with latitude and altitude (Hessen et al., 2007). The extensive data on bird migration does not include quantitative data, however, and access to mark or recapture sites can only be achieved manually, hence a formal analysis of linking zooplankton distribution to migration is not possible, but nevertheless the migration data very well-illustrate the widespread migration across spatial scales.

Judged from such wide-spread migrations across geographical gradients, there should in principle have been sufficient time over the thousands of years since last glaciation to find "everything, everywhere," i.e., a general community homogenization-if birds act as efficient long-distance dispersers, and if not strong, local species sorting was operating. Whether local sorting also promotes community similarity and "quorum effects" is a matter of scale and time, but Jenkins (2006) found poor evidence for such effects in his experimental study. Stochastic events and monopolization effects seem to override quorum effects. While our data not really address community similarity at different scales, we still will argue that local sorting is important for species richness. E.g., it is less likely to become established in a "saturated" community than one with open niches. There clearly also is an abiotic sorting that reduces the likelihood of species to become established in alpine and northern sites compared to southern, productive, warmer and more productive sites, at least during early succession. This could be anticipated if local habitats shared common biotic or abiotic properties. This is simply reflected by the sheere number of species with a southern relative to a northern (or alpine) distribution (Hessen et al., 2007). While there also is a large potential for dispersal from the mainland to the Svalbard archipelago, the very low diversity here is presumably related to climatic factors and even with successful dispersal, there would be a strong constraint on the ability to establish permanent populations despite frequent migration by a number of species (e.g., examples provided in Figure 3).

It is hard to imagine alternatives to birds for long distance dispersal of aquatic crustaceans. We have to admit, however, that we are far from conclusive evidence as to the role of birds in shaping diversity and community patterns at such large, geographical scales. Since many birds, notable geese, mainly forage on terrestrial and coastal sites, and also have a rather fast gut evacuation rate, their ability to serve as long distance vectors may be quite restricted, yet not precluded (Clench and Mathias, 1992).

The more constrained study site at Svalbard, where data on bird influence on specific ponds, as well as data on recent increase in goose populations can be provided, the zooplankton diversity were found to be clearly related to bird activity. An extensive monitoring of geese has been performed over the last years, covering different parts of the season (pre- and postbreeding, breeding, foraging, molting), revealing an extensive 
migration locally and regionally with a strong likelihood of visiting adjacent ponds and lakes (see: http://goosemap.nina.no/ Kartogdata/Kart.aspx). This is also confirmed by recent satellite tracking (unpublished data). Despite these strong indications of zooplankton transmission, we cannot, however, separate the role of birds as vectors due to the confounding impact from productivity of the sites promoted by fertilization from bird droppings and other activities. Also passive transmission by wind is likely over such short distances. Species diversity was primarily related to bird activities, however, and this also holds for clonal (haplotype) diversity of the dominant group Daphnia (Alfsnes et al., 2016). The generally obligate asexual Daphnia spp is the dominant zooplankton and constitutes a large number of clones or haplotypes distributed over a few species or subspecies (Alfsnes et al., 2016). The largest haplotype diversity was always found in bird-influenced localities (Alfsnes et al., 2016). Certain lineages, like European D. pulicaria, has been observed in ponds along the migratory route of birds in northern Norway and the north-western part of Russia (Weider et al., 1999), and both species and haplotype richness is related to bird prevalence (Alfsnes et al., 2016). A more thorough assessment of genetic markers (e.g., haplotypes) along migration routes would, along with experimental studies, serve as the best approach to settle the role of bird zoochory at different geographical scales. Since local species sorting is likely to occur, also this will be a minimum estimate of actual dispersal however. Studies on dispersal and clonal affinities of Daphnia population in Greenland ponds corroborate these findings, and also suggest a prominent role of birds for local dispersal (Haileselasie et al., 2016).

Studies on bird impacts on Arctic freshwaters are biased toward the impacts on aquatic productivity (Milakovic et al., 2001; Van Geest et al., 2007; Côté et al., 2010; MacDonald et al., 2015; Hessen et al., 2017). Some studies do address the impact of seabirds on the biodiversity of Arctic ponds (Keatley et al., 2009; Stewart et al., 2013; Gonzalez-Bergonzoni et al., 2017), but again primarily the indirect impacts by nutrient enrichment. Marine seabirds clearly do not serve as vectors of freshwater invertebrates, but may impact diversity negatively by reducing pH (Gonzalez-Bergonzoni et al., 2017). Also, within Svalbard a very strong local sorting is anticipated, reflected by the strikingly lower diversity in cold sites close to glaciers (Walseng et al., 2018).

One important aspect here is however that birds clearly may play a dual role in shaping diversity and community composition, first by direct dispersal, and secondly by affecting post-dispersal species sorting by increasing water quality and productivity (Mariash et al., 2018). Birds may indeed affect their habitat not only by nutrient release and thereby productivity and community composition among autotroph and thus also zooplankton. They may also affect turbidity and serve as vectors of competitors, predators or parasites. This is also an important aspect of zoochory, since the main concern is primarily how the overall direct and indirect activity of birds affects changes in biogeographical patterns and species richness.

The colonization of artificial ponds over the course of a brief time period should a priori offer the best opportunity to reach conclusions about birds as vectors of invertebrates
(Louette and De Meester, 2005). In this case, it is important that the ponds have some attractive properties for birds (i.e., not simply concrete basins), and also that they offer possibilities for species to establish populations, not only to be transmitted. As pointed out above, the initial likelihood of colonization should a priori be larger in recently established systems with few species and more empty niches. The recently established ponds displayed not only an almost immediate colonization, but also a very high site-specific turnover. In total one third of all recorded Norwegian zooplankton species were recorded in these tiny ponds over the course of the study period, illustrating the strikingly high dispersal ability. The high temporal species turnover likewise suggests that internal competition and species sorting are superimposed on dispersal. Absence from samples in single years does not mean absence from the locality however, and the species could likely be present as resting eggs or dormant stages in the local "seedbank" (Hairston, 1996). Still the high turnover strongly suggests frequent recolonization at the metapopulation level. The studies of these ponds strongly argue for a successful dispersal by birds, with a rapid increase in diversity due to low initial competition and sorting. Firm evidence of bird dispersal is lacking, however, because bird visits or samples from visiting birds were not included-as they rarely are. And this is a key point here. Despite the numerous studies and discussions on richness, diversity and colonization of zooplankton or other freshwater fauna on different spatial and temporal scales, firm evidence is still rare owing to the fact that the numerous studies on diversity and community composition in freshwater habitats so rarely include proper assessments on bird impacts.

It could be argued that since aquatic organisms clearly do disperse, few are endemic and most are widespread, it does not really matter what kind of mechanism mediates the dispersal. Clearly it does. First of all, birds operate over long distance, and as climate change proceeds, they may also serve as vectors of "alien" species. Secondly, if bird dispersal is dominant at all scales, the roles of connectedness are less critical (Havel and Shurin, 2004). Third, the fact that abundance of birds is in strong change, with some groups or species in strong declines, others in strong increase, these changes may profoundly affect freshwater invertebrate communities as well. Thus, it is indeed important also to provide firm evidence for the mode of dispersal, but the hard way of examining birds and their gut content for viable propagules does not prove anything beyond the capacity of birds to serve as vectors, which is hardly disputable (Figuerola et al., 2005).

Even for zooplankton, despite several examples of widespread, sometimes cosmopolitan distributions, it is clearly not so that "everything is everywhere". At local or regional scales, diversity and community composition may primarily be governed by biotic and abiotic properties of the water bodies, as well as connectivity and lake density. Flooding events or dispersal by fish, amphibians or mammals also becomes more likely at local scales. At larger spatial scales, colonization is likely related to bird migration routes (Figuerola and Green, 2002; Green and Figuerola, 2005). Our data suggest spatial explanations dominates over local, and that along longitudinal clines, 
and especially in the case of geographical barriers such as mountain ridges, even 8000 years of post-glaciation history has been insufficient to complete western colonization for most species.

Given the potential fitness-promoting effect of dispersal, one would expect a selective pressure toward abilities to disperse and colonize, and that certain species or taxa have evolved properties promoting "bird-hiking". It could also be anticipated that different taxonomical groups (i.e., cladocera vs. copepods) have different colonization abilities due to considerable differences in features, such as propagules, generation time, and sexual vs. asexual reproduction, implying that Allee effects would benefit asexual cladocera relative to sexually reproducing copepods (Pinel-Alloul et al., 2013; Henriques-Silva et al., 2016). From the literature there is mixed evidence for higher dispersal rates in cladocera. Comparison across taxa done by Cohen and Shurin (2003) could not show any consistent differences between these groups though, instead species of both cladocerans and copepods ranged from highly effective to slow dispersers. Our large-scale data gave no support for this, neither did the very small-scale pond colonization studies, while colonization events at Svalbard hinted on a stronger dispersal ability among cladocera.

At the species level, there are several cases of fast dispersal. E.g., the large, carnivorous cladoceran Bythotrephes longimanus represent a well-documented history with a progressive dispersal over few decades in North America (Yan et al., 2011). In Scandinavia, the herbivorous cladoceran Limnosida frontosa is a large herbivorous species which has colonized a number of Norwegian lakes up to $61^{\circ}$ degree north during the past 100 years (Jensen et al., 2001). There are certain species that typically are confined to coastal areas or north-south valleys and thus implicitly migration routes (e.g. Diaphanosoma brachurum, Daphnia cristata, Bosmina longiriostris, and Simocephalus serrulatus). This may however also reflect temperature preferences, i.e., that colder, and often oligotrophic sites at higher altitudes are avoided.

Dispersal could also work in the opposite direction. The cladoceran Macrothrix hirsuticornis has a holarctic distribution on the northern hemisphere. It is also one of the most common microcrustaceans on Svalbard (Walseng et al., 2018). However, on the Norwegian mainland the species is almost entirely limited to the area between 67,5 and 69,6 northern latitude, except for one record $150 \mathrm{~km}$ further south $(66,2 \mathrm{~N})$. The main distributional area for the species on mainland Norway is also the area where the Svalbard geese leave/enter the Norwegian coast before heading for Svalbard. Hence, it seems possible that M. hirsuticornis colonized mainland Norway from Svalbard. Correspondingly, the calanoid copeod Acanthodiaptomus tibetanus is recorded in Norway only in a few localities in the northernmost county, Finnmark, and in one alpine lake further south. It was possible to relate this distribution to the main migration route of waterfowl from Siberia (Walseng et al., 1996). Similarly, single recordings of Heterocope borealis way off from its main area of distribution may be attributed to birds (Koksvik et al., 2017).
Thus, while assessing dispersal at the species level in specific cases can be tentatively related to birds, it is more difficult to relate general patterns of distribution to birds or any other means of zoochory. By including genetic analysis, not only may the dispersal per se be substantiated, but also the founder or source populations. E.g., the genetic main lineages of Daphnia laevis across North America was found to largely follow migratory patterns of waterfowls (Taylor et al., 1998). Also, Figuerola et al. (2005) related dispersal in Daphnia species to birds by assessing mtDNA to known migration routes, and microsatellite data of bryozoans has also provided strong evidence for bird-mediated dispersal (Okamura and Freeland, 2002).

\section{CONCLUSION}

To assess the role of zoochory is important for several reasons, not the least for understanding the likelihood of "new" species arriving in a changing climate, but also for a full understanding of how ecosystems are connected via migrating animals (Bartels, 2012; Hessen et al., 2017). With dynamic population sizes of waterfowl, their roles as vectors for transmission of aquatic invertebrates is highly relevant for assessment of biogeographical patterns of richness and community composition. Despite the long-lasting interest in the topic, we are still far from a proper understanding of bird-mediated zoochory. By addressing this at three different scales, we illustrate the disparity between circumstantial and firm evidence of bird-mediated zoochory of freshwater zooplankton. We suggest that long distance dispersal is less likely due to the fact that water-fowl commonly forage in terrestrial or coastal habitats and also have a fast gut turnover time. Moreover, local sorting due to different abiotic or biotic properties of recipient water bodies will constrain the permanent establishment of new species, especially when donor and source populations are in different, climatic regions. Short distance zoochory is presumably common, and in recently established habitats this may result in a fast rate of colonization, while in species saturated, established habitats, species sorting is more likely due to strong competitions. Thus, the net impact of zoochory needs to consider both these processes; dispersal and establishment, and these will differ both spatially and temporally. Finally, we conclude that the best line of evidence for dispersal might not be at the species level, but at the genotype level.

\section{AUTHOR CONTRIBUTIONS}

$\mathrm{DH}$ conceived the idea and wrote the first draft. TJ and BW have both been involved in data sampling, analysis and writing of the MS.

\section{FUNDING}

The samplings at Svalbard have been funded by The Research Council of Norway (grant number 227024/E10 and 246726/E10). 


\section{ACKNOWLEDGMENTS}

This work has benefitted from a number of colleagues that has participated in sampling. In particular we would like to

\section{REFERENCES}

Alfsnes, K., Hobæk, A., Weider, L. J., and Hessen, D. O. (2016). Birds, nutrients, and climate change: mtDNA haplotype diversity of arctic daphnia on svalbard revisited. Polar. Biol. 39, 1425-1437. doi: 10.1007/s00300-015-1868-8

Banarescu, P. (1990). Zoogeography of Fresh Waters. General Distribution and Dispersal of Freshwater Animals. Wiesbaden: Aula Verlag.

Bartel, R. D., Sheppard, J. L., Lovas-Kiss, Á, and Green, A. J. (2018). Endozoochory by mallard in New Zealand: what seeds are dispersed and how far? PeerJ 6:e4811. doi: $10.7717 /$ peerj.4811

Bartels, P. (2012). Reciprocal subsidies between freshwater and terrestrial ecosystems structure consumer resource dynamics. Ecology 93, 1173-1182. doi: $10.2307 / 23213511$

Bilton, D. T., Freeland, J. R., and Okamura, B. (2001). Dispersal in freshwater communities. Ann. Rev. Ecol. Syst. 32, 159-181. doi: 10.1146/annurev.ecolsys.32.081501.114016

Bohonak, A. J., and Jenkins, D. G. (2003). Ecological and evolutionary significance of dispersal by freshwater invertebrates. Ecol. Lett. 6, 783-796. doi: 10.1046/j.1461-0248.2003.00486.x

Côté, G., Pienitz, R., Velle, G., and Wang, X. (2010). Impact of geese on the limnology of lakes and ponds from Bylot Island (Nunavut, Canada). Int. Rev. Hydrobiol. 95, 105-129. doi: 10.1002/iroh.200911151

Cácares, C. E., and Soluk, D. A. (2002). Blowing in the wind: a field test of overland dispersal and colonization by aquatic invertebrates. Oecologia 131, 402-408. doi: 10.1007/s00442-002-0897-5

Clench, M. H., and Mathias, J. R. (1992). Intenstinal transit: How can it be delayed long enough for birds to act as long-distance dispersal agents? Auk 109: 933-936. doi: 10.2307/4088179

Cohen, G. M., and Shurin, J. B. (2003). Scale-dependence and mechanisms of dispersal in freshwater zooplankton. Oikos 103, 603-617. doi: 10.1034/j.1600-0706.2003.12660.x

Cottenie, K., and DeMeester, L. (2004). Metacommunity structure: synergy of biotic interactions as selective agents and dispersal fuel. Ecology 85, 114-119. doi: 10.1890/03-3004

Coughlan, N. E., Kelly, T. C., Davenport, J., and Jansen, M. A. K., (2017). Up, up and away: bird-mediated ectozoochorous dispersal between aquatic environments. Freshwater Biol. 62, 631-648. doi: 10.1111/fwb.12894

Darwin, C. R. (1859). On the Origin of Species by Means of Natural selection. London: John Murray

De Meester, L., Gómez, A., Okamura, B., and Schwenk, K. (2002). The monopolization hypothesis and the dispersal-gene flow paradox in aquatic organisms. Acta Oecolo. 23, 121-135 doi: 10.1016/S1146-609X(02)01145-1

de Mendoza, G., Ventura, M., and Catalan, J. (2015). Environmental factors prevail over dispersal constraints in determining the distribution and assembly of Trichoptera species in mountain lakes. Ecol. Evol. 5, 2518-2532. doi: 10.1002 /ece3.1522

Dimante-Deimantovica, I., Walseng, B., Chertoprud, E., and Novichkova, A. (2018). New and previously known species of Copepoda and Cladocera (Crustacea) from Svalbard, Norway-who are they and where do they come from? Fauna Norvegica 38, 18-29. doi: 10.5324/fn.v38i0.2502

Donald, P. F., Gree, R. E., and Heath, M. F. (2001). Agricultural intensification and the collapse of Europe's farmland bird populations. Proc. Biol. Sci. 268, 25-29. doi: $10.1098 /$ rspb.2000.1325

Dussart, B., and Defaye, D. (2006). World Directory of Crustacea Copepoda of Inland Waters. II-Cyclopiformes. Leiden: Backhuys Publishers.

Ekeberg, A. K., and Walseng, B., (2000). Colonization of three newly constructed wetlands in Trøgstad municipality, S.E. Norway. NINA - Fagrapport 043, 1-49.

Figuerola, J., and Green, A. J. (2002). Dispersal of aquatic organisms by waterbirds: a review of past research and priorities for future studies. Freshw. Biol. 47, 483-494. doi: 10.1046/j.1365-2427.2002.00829.x acknowledge Kirsten Christoffersen and Asbjørn Magnar Hov for contribution to the samplings at Svalbard and the southern ponds, respectively, and Håvard Husebø for data and maps on bird migrations.

Figuerola, J.,Green, A. J., and Michot, T. C. (2005). Invertebrate eggs can fly: evidence of waterfowl-mediated gene flow in aquatic invertebrates. Am. Nat. 165, 274-280. doi: 10.1086/427092

Flössner, D. (2000). Die Haplopoda und Cladocera Mitteleuropas. Leiden: Backhuys Publishers.

Fox, A. D. (2010). Current estimates of goose population sizes in Western Europe, a gap analysis and an assessment of trends. Ornis Svecica 20, 115-127.

Frisch, D., Green, A. J., and Figuerola, J. (2007). High dispersal capacity of a broad spectrum of aquatic invertebrates via waterbirds. Aquat. Sci. 69, 568-574. doi: 10.1007/s00027-007-0915-0

Gaston, K. J. (2000). Global patterns in biodiversity. Nature 405, 220-227. doi: $10.1038 / 35012228$

Gonzalez-Bergonzoni, I., Johansen, K. L., Mosbech, A., Landkildehus, F., Jeppesen, E., and Davidson, T. A. (2017). Small birds, big effects: the little auk (Alle alle) transforms high Arctic ecosystems. Proc. Roy. Soc. Biol. Sci. 284:10. doi: $10.1098 / \mathrm{rspb} .2016 .2572$

Gray, D. K., and Arnott, S. E. (2011).Does dispersal limitation impact the recovery of zooplankton communities damaged by a regional stressor? Ecol. Appl. 21, 1241-1256. doi: 10.1890/10-0364.1

Green, A. J. (2016). The importance of waterbirds as an overlooked pathway of invasion for alien species. Divers. Distribut. 22, 239-247. doi: 10.1111/ddi. 12392

Green, A. J., and Figuerola, J. (2005). Recent advances in the study of long-distance dispersal of aquatic invertebrates via birds. Divers. Distribut. 11, 149-156. doi: 10.1111/j.1366-9516.2005.00147.x

Haileselasie, T. H., Mergeay, J., Weider, L. J., Jeppesen, E., and, De Meester, L. (2016). Colonization history and clonal richness of asexual Daphnia in periglacial habitats of contrasting age in West Greenland. J Ani Ecol. 85, 1108-1117. doi: 10.1111/1365-2656.12513

Hairston, N. G. (1996). Zooplankton egg banks as biotic reservoirs in changing environments. Limnol. Oceanogr. 41, 1087-1092. doi: 10.4319/lo.1996.41.5.1087

Havel, J. E., and Shurin, J. B. (2004). Mechanisms, effects, and scales of dispersal in freshwater zooplankton. Limnol. Oceanogr. 49, 1229-1238. doi: 10.4319/lo.2004.49.4 part_2.1229

Hebert, P. D. N., and Wilson, C. C. (1994). Provincialism in plankton: endemism and allopatric speciation in Australian Daphnia. Evolution 48, 1333-1349. doi: 10.1111/j.1558-5646.1994.tb05317.x

Henriques-Silva, R., Pinel-Alloul, B., and Peres-Neto, P. R. (2016). Climate, history and life-history strategies interact in explaining macroecological patterns in freshwater zooplankton. Global Ecol. Biogeogr. 25, 1454-1465. doi: 10.1111/geb.12505

Hessen, D. O., Bakkestuen, V., and Walseng, B. (2007). Energy input and zooplankton species richness. Ecography 30, 749-758. doi: 10.1111/j.2007.0906-7590.05259.x

Hessen, D. O., Faafeng, B. A., Smith, V. H., Bakkestuen, V. H., and Walseng, B. (2006). Extrinsic and intrinsic controls of zooplankton diversity in lakes. Ecology 87, 433-443. doi: 10.1890/05-0352

Hessen, D. O., Tombre, I. M., van Geest, G., and Alfsnes, K. (2017). Global change and ecosystem connectivity: how geese link fields of central Europe to eutrophication of Arctic freshwaters. Ambio 46, 40-47. doi: 10.1007/s13280-016-0802-9

Hov, A. M., and Walseng, B. (2003). Succession in a newly constructed wetland-system in Trøgstad municipality, S.E. Norway. NINA-Fagrapport 74. $1-50$.

Inger, R., Gregory, R., Duffy, J. P., Stott, I., Vorisek, P., and Gaston, K. J. (2014). Common European birds are declining rapidly while les abundant species' are rising. Ecol. Lett. 18, 28-36. doi: 10.1111/ele.12387

Jenkins, D. G. (2006). In search of quorum effects in metacommunity structure: species co-occurrence analyses. 
Ecology $\quad 87, \quad 1523-1531 \quad$ doi: $10.1890 / 0012-9658(2006) 87[1523$ : ISOQEI]2.0.CO;2

Jenkins, D. G., and Buikema, A. L., Jr. (1998). Do similar communities develop in similar sites? A test with zooplankton structure and function. Ecol. Monogra. 68, 421-443. doi: 10.1890/0012-9615(1998)068[0421:DSCDIS]2.0.CO;2

Jenkins, D. G., and Underwood, M. (1998). Zooplankton may not disperse readily in wind, rain, or waterfowl. Hydrobiologia 387/388, 15-21. doi: 10.1023/A:1017080029317

Jensen, T. C., Hessen, D. O., and Faafeng, B. (2001). Biotic and abiotic preferences of cladoceran invader Limnosida frontosa. Hydrobiologia 442, 89-99. doi: 10.1023/A:1017530609557

Keatley, B. E., Douglas, M. S., Blais, J. M., Mallory, M. L., and Smol, J. P. (2009). Impacts of seabird-derived nutrients on water quality and diatom assemblages from Cape Vera, Devon Island, Canadian High Arctic. Hydrobiologia 621, 191-205. doi: 10.1007/s10750-008-9670-z

Koksvik, J. I., Jensen, T. C., and Kjærstad, G. (2017). Heterocope borealis in Norway-A copepod on the move, or on the edge of its natural distribution? Fauna Norvegica 37, 14-19. doi: 10.5324/fn.v37i0.2273

Louette, G., and De Meester, L. (2005). High dispersal capacity of cladoceran zooplankton in newly founded communities. Ecology 86, 353-359. doi: 10.1890/04-0403

Lovas-Kiss, A., Sánches, M. I., Wilkinson, D. M., Coughlan, N. E., Alves, J. A., and Green, A. (2018). Shorebirds as important vectors for plant dispersal in Europe. Ecography 42. 1-12. doi: 10.1111/ecog.04065

MacDonald, L. A., Farquharson, N., Merritt, G., Fooks, S., Medeiros, A. S., Hall, R., et al. (2015). Limnological regime shifts caused by climate warming and Lesser Snow Goose population expansion in the western Hudson Bay Lowlands (Manitoba, Canada). Ecol. Evol. 5, 921-939. doi: 10.1002/ece3.1354

Madsen, J., F., Cottaar, P. I., Nicolaisen, I., Tombre, C., Verscheure, and, E., Kuijken (2013). Svalbard Pink-footed Goose. Population Status Report 2012-2013. Technical Report from DCE-Danish Centre for Environment and Energy, No. 29, Aarhus University, 8 pp. ISBN 978-87-7156-039-8.

Mariash, H. L., Smith, P. A., and Mallory, M. (2018). Decadal response of Arctic freshwater to burgeoning goose populations. Ecosystems 21, 1230-1243. doi: 10.1007/s10021-017-0215-z

Milakovic, B., Carleton, T., and Jefferies, R. L. (2001). Changes in midge (Diptera: Chironomidae) populations of sub-arctic supratidal vernal ponds in response to goose foraging. Ecoscience 8, 58-67. doi: 10.1080/11956860.2001.11682631

Okamura, B., and Freeland, J. R. (2002). "Chapter 10: Gene flow and the evolutionary ecology of passively dispersing aquatic invertebrates," in Dispersal ecology: 42nd symposium of the British Ecological Society, eds J. M. Bullock, R. E. Kenward, and R. S. Hails (Oxford: Cambridge University Press).

Pedersen, Å. Ø., Tombre, I., Jepsen, J. U., Eidesen, P. B., Fuglei, E., and Stien, A. (2013). Spatial patterns of goose grubbing suggest elevated grubbing in dry habitats linked to early snow melt. Polar Res. 32:19719. doi: 10.3402/polar.v32i0.19719

Pinel-Alloul, B., André, A., Legendre, P., Cardille, J. A., Patalas, K., and Salki, A. (2013). Large-scale geographic patterns of diversity and community structure of pelagic crustacean zooplankton in Canadian lakes. Glob. Ecol. Biogeogr. 22, 784-795. doi: 10.1111/geb.12041

Shurin, J. B. (2000). Dispersal limitation, invasion resistance, and the structure of pond zooplankton communities. Ecology 81, 3074-3086. doi: 10.1890/0012-9658(2000)081[3074:DLIRAT]2.0.CO;2

Simonis, J. L., and Ellis, J. C. (2014). Bathing birds bias beta-diversity: frequent dispersal by gulls homogenizes fauna in a rock-pool metacommunity. Ecology 95, 1545-1555. doi: 10.1890/13-1185.1
Stewart, E. M., Michelutti, N., Blais, J. M., Mallory, M. L., Douglas, M. S. V., and Smol, J. P. (2013). Contrasting the effects of climate, nutrient, and oxygen dynamics on subfossil chironomid assemblages: a paleolimnological experiment from eutrophic high Arctic ponds. J. Paleolimnol. 49, 205-209. doi: 10.1007/s10933-012-9658-6

Taylor, D. J., Finston, T. L., and Hebert, P. D. N. (1998). Biogeography of a widespread freshwater crustacean: pseudocongruence and cryptic endemism in the North American Daphnia laevis complex. Evolution 52, 1648-1670. doi: 10.1111/j.1558-5646.1998.tb02245.x

Van Geest, G. J., Hessen, D. O., Spierenburg, P., Dahl-Hansen, G. A., Christensen, G., Faerovig, P. J., et al. (2007). Goose-mediated nutrient enrichment and planktonic grazer control in arctic freshwater ponds. Oecologia 153, 653-662 doi: 10.1007/s00442-007-0770-7

Ventura, M., Petrusek, A., Miró, A., Hamrová, E., Buñay, E., De Meester, L., and, Mergeay, J. (2014). Local and regional founder effects in lake zooplankton persist after thousands of years despite high dispersal potential. Mol. Ecol. 23,1014-1027. doi: 10.1111/mec.12656

Walseng, B., Halvorsen, G., and Hessen, D. O. (2006). Major contribution from littoral crustaceans to zooplankton species richness in lakes. Limnol. Oceanogr. 51, 2600-2606. doi: 10.4319/lo.2006.51.6.2600

Walseng, B., Halvorsen, G., Huru, H., Nøst, T., and Scartau, A. K. L. (1996). Acanthodiaptomus tibetanus Daday, 1908 (Copepoda, Calanoida, Diaptomidae): new records of a very rare species. Crustaceana 69, 868-877.

Walseng, B., Jensen, T., Dimante-Deimantovica, I., Christoffersen, K. S., et al. (2018). Freshwater diversity in Svalbard: providing baseline data for ecosystems in change. Polar Biol. 41, 1995-2005. doi: 10.1007/s00300-0182340-3

Weider, L. J., Hobaek, A., Colbourne, J. K., Crease, T. J., Dufresne, F., Hebert, P. D. (1999). Holarctic phylogeography of an asexual species complex I. Mitochondrial DNA variation in Arctic Daphnia. Evolution 53, 777-792 doi: 10.1111/j.1558-5646.1999.tb05372.x

Weider, L. J., Lampert, W., Wessels, M., Colbourne, J. K., Limburg, P. (1997). Long-term genetic shifts in a microcrustacean egg bank associated with anthropogenic changes in the Lake Constance ecosystem. Proc. R Soc. Lon. B 264, 1613-1618. doi: 10.1098/rspb.1997.0225

Yan, N. D., Leung, B., Lewis, M. A., and Peacor, S. D. (2011). The spread, establishment and impacts of the spiny water flea, Bythotrephes longimanus in temperate North America: a synopsis of the special issue. Biol. Inv. 13, 2423-2432. doi: 10.1007/s10530-011-0069-9

Zeller, M., Reuch, T. B. H., and Lampert, W. (2006). A comparative population genetic study on calanoid freshwater copepods: Investigation of isolation-bydistance in two Eudiaptomus species with a different potential for dispersal. Limnol. Oceanograp. 51, 117-124. doi: 10.4319/lo.2006.51.1.0117

Conflict of Interest Statement: The authors declare that the research was conducted in the absence of any commercial or financial relationships that could be construed as a potential conflict of interest.

Copyright (C) 2019 Hessen, Jensen and Walseng. This is an open-access article distributed under the terms of the Creative Commons Attribution License (CC BY). The use, distribution or reproduction in other forums is permitted, provided the original author(s) and the copyright owner(s) are credited and that the original publication in this journal is cited, in accordance with accepted academic practice. No use, distribution or reproduction is permitted which does not comply with these terms. 